\title{
Comparison of inhaled and intravenous terbutaline in acute severe asthma
}

\author{
SJ WILLIAMS, SJ WINNER, TJH CLARK
}

From the Brompton Hospital, London

ABSTRACT In patients with acute severe asthma, $5 \mathrm{mg}$ of terbutaline by inhalation and $500 \mu \mathrm{g}$ intravenously in divided doses both produced equally effective but not maximal bronchodilatation. There was no difference in the production of side-effects. These results support the view that inhaled therapy can be as effective in patients with acute severe asthma as injected treatment. In view of the risks of intravenous treatment, especially using high doses, inhaled bronchodilator therapy would seem advisable as initial treatment.

In severe asthma, bronchodilators are usually given intravenously or by inhalation. We report a doubleblind crossover study which compared the bronchodilation produced by a $\beta_{2}$ agonist (terbutaline) given intravenously and by inhalation to determine effectiveness and the optimal dose of terbutaline by each route.

\section{Methods}

Fifteen patients admitted to hospital with severe acute asthma $\left(\mathrm{Po}_{2}<70 \mathrm{mmHg}\right.$, pulse $>100 / \mathrm{min}$, $\mathrm{FEV}_{1}<25 \%$ predicted) were studied. Patients who had been given inhaled or intravenous bronchodilators within the previous two hours were excluded. All gave their formal consent. Their FEV 1 and FVC (best of three attempts) and pulse rate, were recorded on admission and again 10 minutes later. If the recordings were stable (within $\pm 10 \%$ ) the study was continued. The patients were then given either terbutaline $250 \mu \mathrm{g}$ intravenously and $5 \mathrm{ml}$ of saline by nebuliser simultaneously over 10 minutes, or saline by intravenous injection and $2.5 \mathrm{mg}$ of terbutaline by nebuliser simultaneously over 10 minutes.

Spirometry (best of three recordings) and pulse rate were recorded immediately after completion of each treatment and at five-minute intervals until there was no further improvement in FEV . The treatment was then repeated using the same route for the active drug and further measurements re-

Address for reprint requests: Professor TJH Clark, Brompton Hospital, Fulham Road, London SW3 6HP. corded. When a new $\mathrm{FEV}_{1}$ plateau had been reached, terbutaline was given in the same two doses using the other route and the same measurements recorded.

Patients therefore received $2.5 \mathrm{mg}$ of terbutaline by inhalation $\times 2$ followed by $250 \mu \mathrm{g}$ of terbutaline intravenously $\times 2$ or $250 \mu \mathrm{g}$ of terbutaline intravenously $\times 2$ followed by $2.5 \mathrm{mg}$ of terbutaline by inhalation $\times 2$. Each injection and inhalation was given over 10 minutes. The drugs were identified by code number only and the order of treatment was allocated randomly. Other treatment for severe asthma-for example, hydrocortisone $200 \mathrm{mg}$ six-hourly and oxygen-was given concurrently in all cases but intravenous aminophylline was not used.

\section{Results}

In eight patients terbutaline was first given intravenously and then by inhalation. In seven patients the active drug was initially given by inhalation and then intravenously. The results are shown in the figure.

Both routes produced significant improvement in $F V_{1}$ and $F V C$ and fall in pulse rate and there was no significant difference between them. Neither $5 \mathrm{mg}$ inhaled terbutaline nor $500 \mu \mathrm{g}$ of intravenous terbutaline produced maximal bronchodilation, as all measurements were still improving even after both routes had been employed. No important adverse side-effects were found when the active drug was given by either route. Tremor was equally common (three cases). 

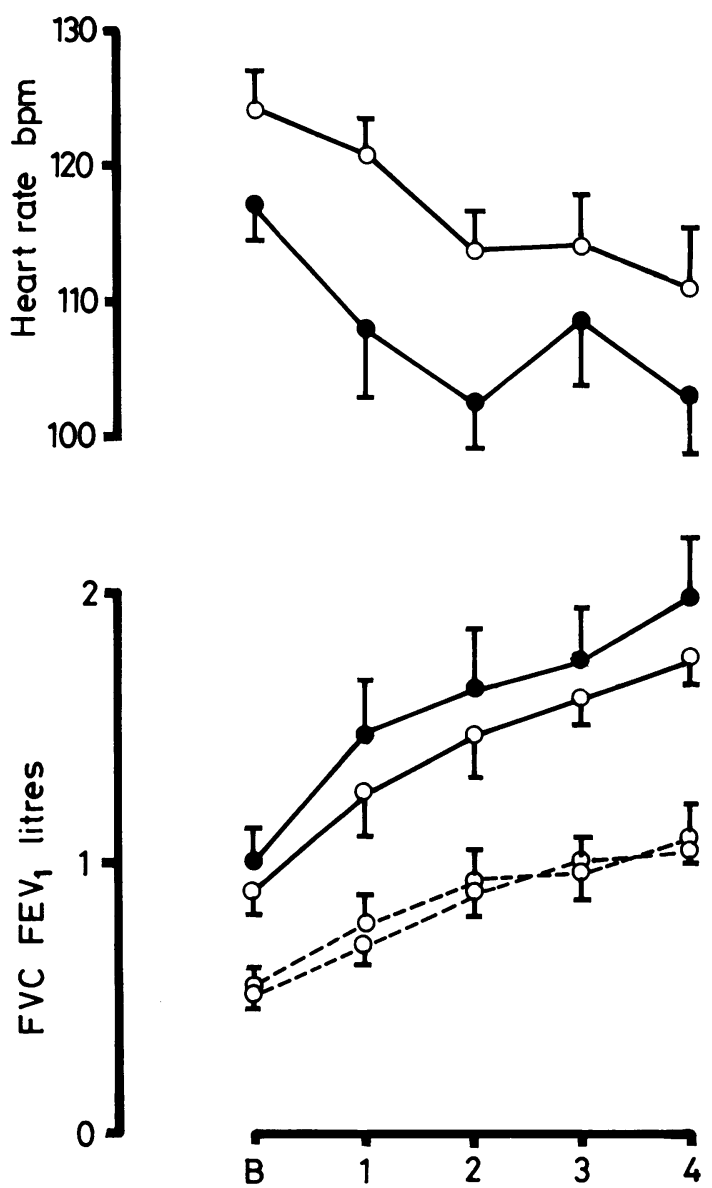

Figure Response of pulse rate, $F E V_{1}$, and vital capacity to terbutaline. $\bigcirc=$ patients initially given treatment by intravenous route $(1+2)$ followed by inhaled route $(3+4) .0=$ patients initially given treatment by inhaled route $(1+2)$ followed by intravenous route $(3+4) . B=$ baseline measurements.

\section{Discussion}

Controlled therapeutic trials in acute severe asthma are difficult to do and interpret but our results show clearly that bronchodilatation could be achieved equally well be inhalation as by injection in the patients we studied. These patients were selected at random from those admitted with severe asthma and are likely to be representative. The trial design was satisfactory, although by chance the patients receiving intravenous treatment first probably had more severe asthma despite randomisation and this is seen by their faster heart rate. Ventilatory indices and basal arterial oxygen tensions were comparable for both treatment groups.
The results showed bronchodilation to be independent of route of administration. In view of the clinical circumstances our study was kept as simple as possible and arterial oxygen tension was not followed during treatment, and we therefore cannot exclude differences in response of blood gases to the routes of administration. Although there were no differences in response between the two treatment groups the rise in the heart rate when the first intravenous dose of terbutaline was given to those who had initially been treated by inhalation is probably of clinical significance as it indicates the potential disadvantage of injected therapy. Our results do not show this as convincingly as previously reported, ${ }^{12}$ but lead to a similar conclusion that inhaled therapy minimises the risks of systemic sideeffects.

We carried out this study because the choice of bronchodilator, its route of administration, and optimal dose in patients with life-threatening asthma are still subjects of controversy. The $\beta_{2}$ agonist salbutamol, given intravenously, has been shown to be as effective as aminophylline and less likely to cause nausea and vomiting. ${ }^{3}$ Lawford $e t a l^{2}$ found that in severely ill patients intravenous salbutamol produced tremor and tachycardia whereas nebulised salbutamol did not. By contrast, in another study, intravenous salbutamol was shown to produce effective bronchodilation in patients who had failed to respond satisfactorily to inhaled salbutamol. ${ }^{4}$ However, Bloomfield et al ${ }^{1}$ found that both intravenous and inhaled salbutamol produced a significant improvement in peak expiratory flow but intravenous salbutamol resulted in an increase in heart rate while the inhaled drug did not and relief of pulsus paradoxus was significantly better after inhaled rather than intravenous treatment.

The most likely explanation for the different results of these and similar studies, and for differences in opinion about the best route of administration of bronchodilator, lies in the selection of patients. Most studies have to exclude very sick patients and it is still possible that those asthmatics with very severe airways obstruction might respond better to injected treatment. If studies include such patients, different results might be found. Our results and others published, however, strongly support the view that asthmatic patients with severe airways obstruction can respond satisfactorily to inhaled treatment and by doing so will be less at risk from systemic toxicity. The similarity of response of $F E V_{1}$ and $V C$ seen in the figure suggests both routes have a comparable effect on large and small airways obstruction and provides further evidence for the effectiveness of inhaled bronchodilator therapy in patients with acute severe asthma 
admitted to hospital. Thus, despite severe airways obstruction, inhaled bronchodilators can achieve comparable bronchodilation to intravenous treatment and, as systemic toxicity is less likely, it seems sensible to try inhaled therapy first in patients suffering from acute severe asthma.

\section{References}

1 Bloomfield P, Carmichael J, Petrie GR, Jewell NP,
Crompton GK. Comparison of salbutamol given intravenously and by intermittent positive-pressure breathing in life-threatening asthma. Br Med J 1979; 1:848.

${ }^{2}$ Lawford P, Jones BJM, Milledge JS. Comparison of intravenous and nebulised salbutamol in initial treatment of severe asthma. Br Med J 1978;1:84.

${ }^{3}$ Williams SJ, Parrish RW, Seaton A. Comparison of intravenous aminophylline and salbutamol in severe asthma. Br Med J 1975;4:685.

4 Williams SJ, Seaton A. Intravenous or inhaled salbutamol in severe acute asthma? Thorax 1977;32:555. 